\title{
Intense and Stable Near-Infrared Emission from Light-Emitting Electrochemical Cells Comprising a Metal-Free Indacenodithieno[3,2-b]thiophene-Based Copolymer as the Single Emitter
}

\author{
Shi Tang, ${ }^{\dagger, \dagger, \perp}$ Petri Murto, ${ }^{\S, \perp}$ Xiaofeng Xu, ${ }^{\S}$ Christian Larsen, ${ }^{\dagger, \ddagger}$ Ergang Wang, ${ }^{*} \S$ \\ and Ludvig Edman*, $*, \ddagger$ (1) \\ ${ }^{\dagger}$ The Organic Photonics and Electronics Group, Umeå University, SE-90187 Umeå, Sweden \\ ${ }^{\ddagger}$ LunaLEC AB, Tvistevägen 47, SE-907 19 Umeå, Sweden \\ ${ }^{\S}$ Department of Chemistry and Chemical Engineering/Applied Chemistry, Chalmers University of Technology, SE-412 96 \\ Gothenburg, Sweden
}

Supporting Information

\begin{abstract}
We report on the synthesis, characterization, and application of a series of metal-free near-infrared (NIR) emitting alternating donor/acceptor copolymers based on indacenodithieno[3,2-b] thiophene (IDTT) as the donor unit. A light-emitting electrochemical cell (LEC), comprising a blend of the copolymer poly[indacenodithieno[3,2-b]thiophene-2,8-diyl-alt-2,3-diphenyl-5,8-di(thiophen-2-yl)quinoxaline-5,5'-diyl] and an ionic liquid as the single-layer active material sandwiched between two air-stable electrodes, delivered NIR emission $\left(\lambda_{\text {peak }}=705 \mathrm{~nm}\right)$ with a high radiance of $129 \mu \mathrm{W} / \mathrm{cm}^{2}$ when driven by a low voltage of $3.4 \mathrm{~V}$. The NIR-LEC also featured good stress stability, as manifested in that the peak NIR output from a nonencapsulated device after

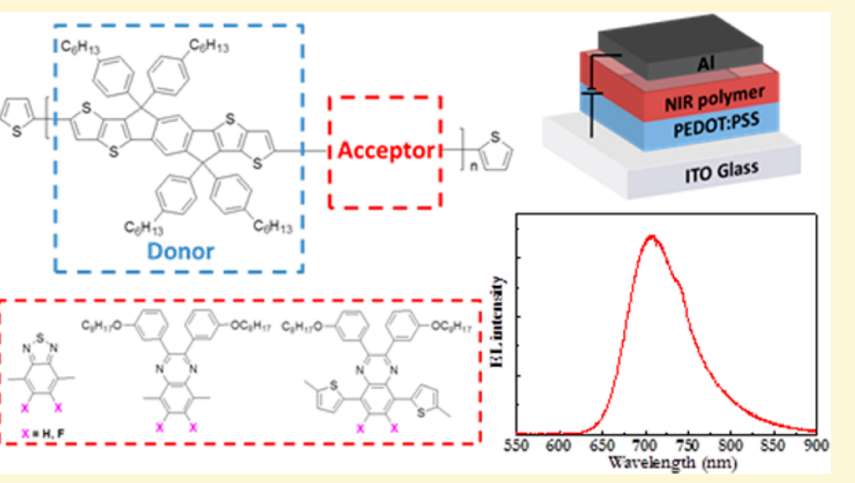
$24 \mathrm{~h}$ of continuous operation only had dropped by $3 \%$ under $\mathrm{N}_{2}$ atmosphere and by $27 \%$ under ambient air. This work accordingly introduces IDTT-based donor/acceptor copolymers as functional metal-free electroluminescent materials in NIRemitting devices and also provides guidelines for how future NIR emitters should be designed for further improved performance.
\end{abstract}

\section{INTRODUCTION}

Near-infrared (NIR) emitting devices-which are low-cost, lightweight, thin, and conformable and which can deliver strong and efficient NIR emission when driven by the low voltage of a battery-are of interest for a wide range of portable applications in, e.g., medicine, ${ }^{1,2}$ security, ${ }^{3}$ and optical communication. ${ }^{4,5}$ The most common low-voltage technology that fulfills these form-factor requirements is the organic lightemitting diode (OLED); Cocchi and co-workers ${ }^{6,7}$ and Tuong Ly et al., ${ }^{8}$ as well as several other research groups, ${ }^{9-16}$ have reported on OLED devices that deliver intense and efficient NIR emission. These NIR-OLEDs typically comprise a complex multilayer active material that is processed under high vacuum and a low-work function cathode that is unstable under ambient air; these characteristic features unfortunately result in a relatively expensive fabrication.

The light-emitting electrochemical cell (LEC) is an alternative low-voltage technology that can deliver the desired form factors but in addition can comprise solely air-stable materials and as a consequence be fabricated with low-cost, solution-based methods. ${ }^{17-24}$ NIR emission from LEC devices has most commonly been effectuated with a transition-metalbased compound as a key constituent in the active material, but such rare-metal-based NIR-LECs have only been reported to emit with a rather modest intensity of $<50 \mu \mathrm{W} / \mathrm{cm}^{2}{ }^{25-31}$ Bolink and co-workers introduced an interesting active material from a sustainability viewpoint in the form of a metal-free, cyanine-based host-guest blend and were able to obtain intense NIR emission of $170 \mu \mathrm{W} / \mathrm{cm}^{2}$ when the corresponding device was driven by a high-frequency pulsed current. ${ }^{32}$ However, for battery-driven portable applications this operational mode will require the inclusion of a cost-driving

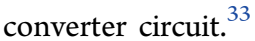

Here, we report on the synthesis and characterization of a series of indacenodithieno[3,2-b] thiophene (IDTT)-based conjugated copolymers and demonstrate that LEC devices comprising a solution-processed metal-free blend of an IDTTbased copolymer and an ionic liquid sandwiched between two

Received: May 18, 2017

Revised: $\quad$ August 22, 2017

Published: August 22, 2017 
air-stable electrodes deliver a promising NIR performance. Specifically, NIR emission $\left(\lambda_{\text {peak }}=705 \mathrm{~nm}\right.$, fwhm $=85 \mathrm{~nm}$ ) with a high radiance of $129 \mu \mathrm{W} / \mathrm{cm}^{2}$ at an external quantum efficiency of $0.10 \%$ was attained when the LEC device was driven by a low dc voltage of $3.4 \mathrm{~V}$. It is notable that the NIR output from a nonencapsulated device only dropped by $3 \%$ under inert atmosphere and by $27 \%$ under ambient air following 1 day of uninterrupted operation. An efficiency analysis reveals that future work toward metal-free NIR-LEC with further improved performance should primarily be directed toward improving the photoluminescence quantum yield (PLQY) of the copolymer but also aim for a balanced $\mathrm{p}$ type and $n$-type doping capacity.

\section{EXPERIMENTAL SECTION}

Materials and Synthesis. We have followed procedures outlined in the scientific literature for the synthesis of the $m$-hexylphenylsubstituted (indacenodithieno[3,2-b] thiophene-2,8-diyl)bis(trimethylstannane) (IDTT-m) donor monomer ${ }^{34,35}$ and for the dibromo-substituted acceptor monomers benzo $[c][1,2,5]$ thiadiazole (BT), ${ }^{36}$ 5,6-difluorobenzo[c] $[1,2,5]$ thiadiazole (BTF), ${ }^{37,38}$ 2,3-diphenylquinoxaline $(\mathrm{Q}),^{39,40}$ 6,7-difluoro-2,3-diphenylquinoxaline $(\mathrm{QF}){ }^{41}$ 2,3-diphenyl-5,8-di(thiophen-2-yl)quinoxaline (TQ), ${ }^{42}$ and 6,7-difluoro-2,3-diphenyl-5,8-di(thiophen-2-yl)quinoxaline (TQF). ${ }^{41,43,44}$ The $p$-hexylphenyl-substituted (indacenodithieno[3,2- $b]$ thiophene2,8-diyl)bis(trimethylstannane) (IDTT-p) donor monomer was purchased from Solarmer Materials, while the other reagents and solvents were obtained from Sigma-Aldrich. All purchased materials were used as received. The chemical structures of the monomers and the corresponding copolymers are disclosed in Figure S1 in the Supporting Information.

Equal amounts of the bis(trimethylstannyl)-substituted donor monomer (IDTT-m or IDTT- $\mathrm{p}, 0.150 \mathrm{mmol}, 1.0$ equiv) and the dibromo-substituted acceptor monomer (BT, BTF, Q QF, TQ or TQF, $0.150 \mathrm{mmol}, 1.0$ equiv) were included in a $25 \mathrm{~mL}$ 2-neck flask, and then $\mathrm{Pd}_{2}(\mathrm{dba})_{3}(2.75 \mathrm{mg}, 0.003 \mathrm{mmol})$ and tri $(o$-tolyl $)$ phosphine (3.65 mg, $0.012 \mathrm{mmol}$ ) were added. The mixture was subjected to 5 vacuum/nitrogen backfill cycles before $12 \mathrm{~mL}$ of anhydrous toluene was added. The blend was heated to $90{ }^{\circ} \mathrm{C}$ under $\mathrm{N}_{2}$ atmosphere and stirred vigorously for $24 \mathrm{~h}$. Thereafter, 2-(tributylstannyl)thiophene $(0.180 \mathrm{mmol}, 1.2$ equiv) was added to the flask followed by $1 \mathrm{~h}$ of heating at $90{ }^{\circ} \mathrm{C}$. Thereafter, 2-bromothiophene $(0.210 \mathrm{mmol}, 1.4$ equiv) was added followed by an additional $1 \mathrm{~h}$ of heating. The flask was then allowed to cool to room temperature, after which the copolymer was precipitated by dropping the reaction mixture slowly into acetone. The copolymer was collected by filtration and washed with Soxhlet extraction using acetone, diethyl ether, and chloroform. The chloroform fraction was further purified by passing through a short silica gel column. The copolymer was once more precipitated into acetone and collected by filtration through a $0.45 \mu \mathrm{m}$ Teflon filter. Finally, the copolymer was collected by drying under vacuum at $40{ }^{\circ} \mathrm{C}$ for $12 \mathrm{~h}$. Information on the appearance, yield, number-average molecular weight $\left(M_{\mathrm{n}}\right)$, and polydispersity index (PDI) are presented below for each of the synthesized copolymers:

Poly [indacenodithieno $[3,2-b]$ thiophene-2,8-diyl-alt-benzo[c][1,2,5]thiadiazole-4,7-diyl] (PIDTT-BT). Collected as dark-blue solid. Yield, 70\%; GPC, $M_{\mathrm{n}}=102.2 \mathrm{~kg} / \mathrm{mol}$; PDI $=5.0$.

Poly [indacenodithieno [3,2-b] thiophene-2,8-diyl-alt-5,6difluorobenzo[c][1,2,5] thiadiazole-4,7-diyl] (PIDTT-BTF). Collected as dark-blue solid. Yield, $63 \%$; GPC, $M_{\mathrm{n}}=11.8 \mathrm{~kg} / \mathrm{mol}$; PDI $=2.5$.

Poly[indacenodithieno[3,2-b] thiophene-2,8-diyl-alt-2,3-bis (3(octyloxy)phenyl)quinoxaline-5,8-diyl] (PIDTT-Q). ${ }^{35}$ Collected as dark-purple/blue solid. Yield, 74\%; GPC, $M_{\mathrm{n}}=33.2 \mathrm{~kg} / \mathrm{mol}$; PDI = 2.9.

Poly[indacenodithieno[3,2- $b$ ] thiophene-2,8-diyl-alt-6,7-difluoro2,3-bis(3-(octyloxy)phenyl)quinoxaline-5,8-diyl] (PIDTT-QF). ${ }^{35} \mathrm{Col}-$ lected as dark-purple/blue solid. Yield, $60 \%$; GPC, $M_{\mathrm{n}}=14.1 \mathrm{~kg} / \mathrm{mol}$; PDI $=2.2$.
Poly[indacenodithieno[3,2-b] thiophene-2,8-diyl-alt-2,3-bis (3(octyloxy)phenyl)-5,8-di(thiophen-2-yl)quinoxaline-5,5' -diyl] (PIDTT-TQ). Collected as dark-purple solid. Yield, 66\%; GPC, $M_{\mathrm{n}}=$ $97.0 \mathrm{~kg} / \mathrm{mol}$; PDI $=5.7$.

Poly[indacenodithieno[3,2-b] thiophene-2,8-diyl-alt-6,7-difluoro2,3-bis(3-(octyloxy)phenyl)-5,8-di(thiophen-2-yl)quinoxaline-5,5' diyl] (PIDTT-TQF). Collected as dark-purple solid. Yield, 58\%; GPC, $M_{\mathrm{n}}=152.4 \mathrm{~kg} / \mathrm{mol} ;$ PDI $=2.7$.

Characterization. ${ }^{1} \mathrm{H}$ NMR $(400 \mathrm{MHz})$ was performed on an automated Varian Inova $400 \mathrm{MHz}$ NMR spectrometer, and the ${ }^{1} \mathrm{H}$ NMR spectra for the six copolymers are presented in Figures S2-S4 in the Supporting Information. The molecular weight was measured by size-exclusion chromatography (SEC) at $150{ }^{\circ} \mathrm{C}$ with $1,2,4-$ trichlorobenzene as the eluent, using an Agilent PL-GPC 220 Integrated High-Temperature GPC/SEC system equipped with refractive-index and viscometer detectors and three sequential PLgel $10 \mu \mathrm{m}$ MIXED-B LS $300 \times 7.5 \mathrm{~mm}$ columns. $M_{\mathrm{n}}$ was calculated using polystyrene as the calibration standard. The thermogravimetric analysis (TGA) was performed under $\mathrm{N}_{2}$ with a heating rate of 10 ${ }^{\circ} \mathrm{C} / \mathrm{min}$ using a Mettler Toledo TGA/DSC 3+ STAR System instrument. The solution absorption spectra were measured in dilute toluene solutions $(<0.001 \%)$ in $10 \times 10 \mathrm{~mm}^{2}$ quartz cuvettes using a Varian Cary 50 Bio UV-vis spectrophotometer. The temperaturedependent absorption spectra were measured in $1 \%$ chlorobenzene solutions, using a Varian Cary 100 Bio UV-vis spectrophotometer connected to a Varian Cary Temperature Controller unit. The solution photoluminescence (PL) spectra were measured on dilute toluene solutions $(<0.001 \%)$, and the temperature-dependent PL spectra were measured on $1 \%$ chlorobenzene solutions, using a Varian Cary Eclipse Fluorescence spectrophotometer. The solution PL quantum yield (PLQY) was measured with a $540 \mathrm{~nm}$ excitation beam and with Cresyl Violet in ethanol as the standard (PLQY $=54 \%) .{ }^{45}$ The solid-state absorption, PL, and PLQY were measured on thin films deposited on quartz substrates using a PerkinElmer Lambda 35 UV-vis spectrophotometer, a PerkinElmer LS 45 fluorescence spectrometer, and an absolute PLQY spectrometer (C9920, Hamamatsu), respectively.

The cyclic voltammetry $(\mathrm{CV})$ measurements were carried out under $\mathrm{N}_{2}$ atmosphere using a CH-Instruments $650 \mathrm{~A}$ Electrochemical Workstation. The working electrode comprised the copolymer film under study on a Pt wire, as fabricated by dropping $\sim 0.1 \mathrm{~mL}$ of a 10 $\mathrm{mg} / \mathrm{mL}$ copolymer-in-chlorobenzene solution onto the Pt wire using a pipet, the counter electrode was a $\mathrm{Pt}$ wire, the pseudoreference electrode comprised an $\mathrm{Ag}$ wire in $0.1 \mathrm{M} \mathrm{AgNO}_{3}\left(\mathrm{MeCN} / \mathrm{H}_{2} \mathrm{O}\right)$, and the electrolyte was $0.1 \mathrm{M}$ tetrabutylammonium hexafluorophosphate $\left(\mathrm{TBAPF}_{6}\right)$ in anhydrous acetonitrile. The electrolyte was bubbled with $\mathrm{N}_{2}$ gas prior to the measurement in order to remove any oxygen residues. The pseudoreference electrode was calibrated versus the ferrocene/ferrocenium $\left(\mathrm{Fc} / \mathrm{Fc}^{+}\right)$redox couple at the end of the measurement. The oxidation and reduction scans were measured separately on pristine copolymer films, and at least four independent scans were performed for each copolymer. The oxidation potential $\left(E_{\mathrm{ox}}\right)$ and the reduction potential $\left(E_{\mathrm{red}}\right)$ were defined as the intersection of the baseline with the tangent of the current at the half-peak height.

DFT Calculation. The density functional theory (DFT) calculations were carried out with the Gaussian 09 package, ${ }^{46}$ and the geometry optimization was performed in gas phase at the B3LYP/6$31 \mathrm{G}(\mathrm{d}, \mathrm{p})^{47-50}$ level. Shorter oligomer structures, comprising 1,2 , or 3 repeat units and with the long alkyl and alkyloxy side chains replaced by shorter methyl and methoxy groups, were commonly used as model compounds in the calculations, because the larger polymeric structures result in prohibitively long computational times. We have also performed DFT control calculations at the $\omega \mathrm{B} 97 \mathrm{XD} / 6-31 \mathrm{G}(\mathrm{d}, \mathrm{p})$ level, because this functional has been reported to deliver more realistic torsion energy barrier. ${ }^{51-54}$ Figure S5 in the Supporting Information demonstrates that both methods result in the same minimum-energy conformation and torsional angle but that the $\omega \mathrm{B} 97 \mathrm{XD}$ functional as expected delivered a lower torsion energy barrier. 
(a)

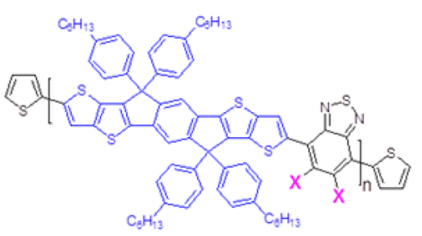

$\mathrm{X}=\mathrm{H}:$ PIDTT-BT $\mathrm{X}=\mathrm{F}:$ PIDTT-BTF

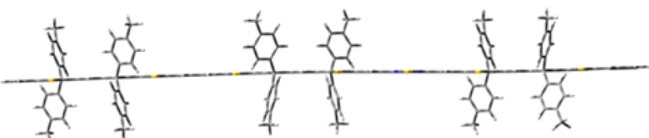

(b)

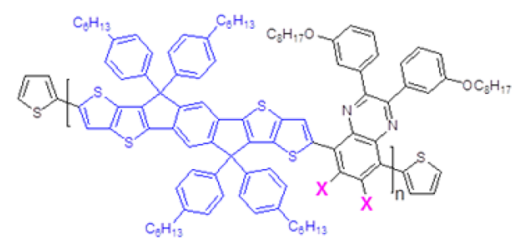

$\mathrm{X}=\mathrm{H}$ : PIDTT-Q $\mathrm{X}=\mathrm{F}$ : PIDTT-QF

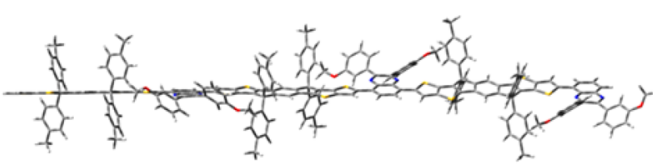

(c)

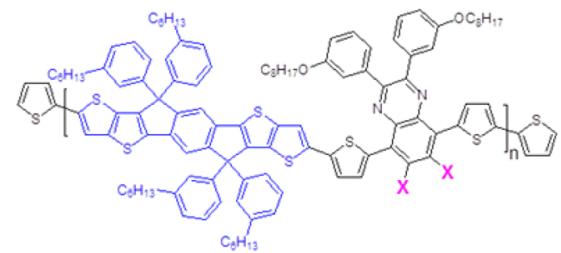

$\mathrm{X}=\mathrm{H}:$ PIDTT-TQ $\mathrm{X}=\mathrm{F}:$ PIDTT-TQF
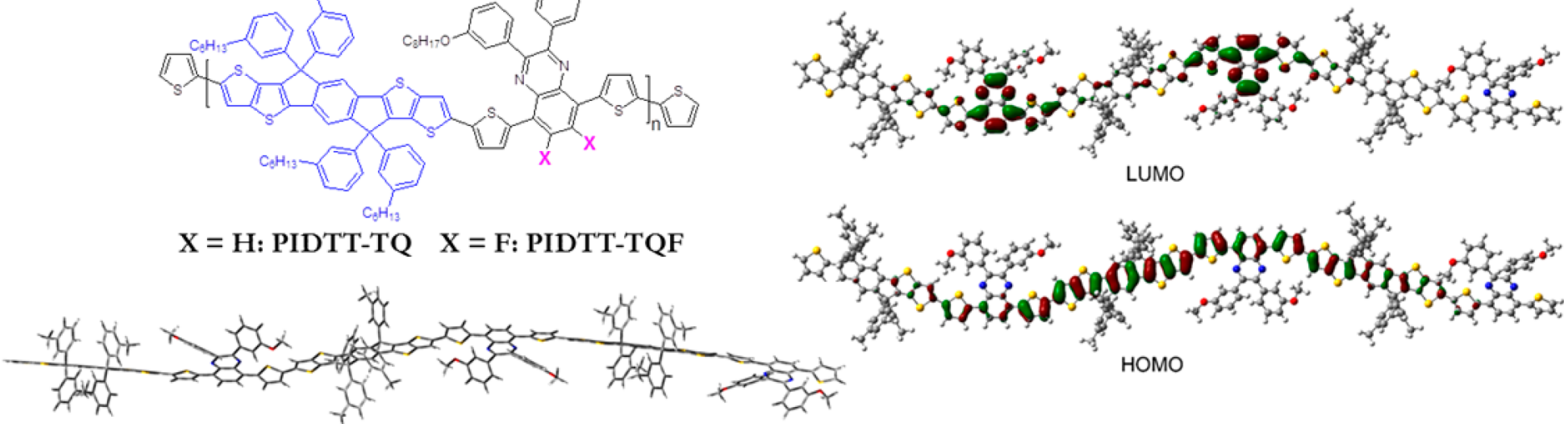

LUMO

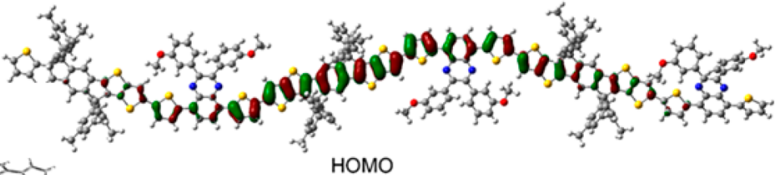

Figure 1. (upper left) Chemical structures of the conjugated donor/acceptor copolymers, with the side-chain functionalized IDTT donor unit positioned to the left indicated by blue color. The conformation (lower left) and the lowest unoccupied molecular orbital (LUMO)/highest occupied molecular orbital (HOMO) density (right) of the corresponding geometry-optimized three-repeat unit oligomers, as calculated with DFT.

Device Fabrication and Characterization. The copolymers and the tetrahexylammonium tetrafluoroborate $\left(\mathrm{THABF}_{4}\right)$ ionic liquid were dissolved separately in chlorobenzene, with the concentration being $12.5 \mathrm{mg} / \mathrm{mL}$ (PIDTT-BT, PIDTT-TQ, and PIDTT-TQF), 15 $\mathrm{mg} / \mathrm{mL}$ (PIDTT-Q), $20 \mathrm{mg} / \mathrm{mL}$ (PIDTT-QF and PIDTT-BTF), and $10 \mathrm{mg} / \mathrm{mL}\left(\mathrm{THABF}_{4}\right)$. The active-material ink was prepared by blending the copolymer and $\mathrm{THABF}_{4}$ solutions in a copolymer/ $\mathrm{THABF}_{4}$ mass ratio of 10:1. A layer of poly(3,4-ethylenedioxythiophene)-poly(styrenesulfonate) (PEDOT-PSS, Clevios P VP AI 4083, Heraeus) was spin-coated at $4000 \mathrm{rpm}$ for $60 \mathrm{~s}$ onto carefully cleaned indium-tin-oxide (ITO)-coated glass substrates (20 $\Omega$ / square, Thin Film Devices, U.S.A.). The active-material ink was stirred on a magnetic hot plate at $343 \mathrm{~K}$ for at least $12 \mathrm{~h}$ and thereafter spincoated onto the PEDOT-PSS layer at $2000 \mathrm{rpm}$ for $60 \mathrm{~s}$. The dry thicknesses of the PEDOT-PSS and active-material layers were 40 and $80 \mathrm{~nm}$, respectively. A set of four $\mathrm{Al}$ electrodes was deposited on top of the active material by thermal evaporation at $p<5 \times 10^{-4} \mathrm{~Pa}$. The light-emission area, as defined by the cathode-anode overlap, was $0.2 \times 0.2 \mathrm{~cm}^{2}$. The LECs were driven by a constant-current circuit, and the voltage was logged by a microcontroller board (Arduino UNO) connected to a computer. The ITO electrode was invariably biased as the positive anode, and the $\mathrm{Al}$ was the cathode. The emitted radiance was measured with a calibrated Si photodiode (S2387-33R, Hamamatsu), and the emission spectrum was detected with a spectrometer (USB2000+, Ocean Optics). All of the above procedures, except for the deposition of the PEDOT/PSS layer, were carried out in two interconnected $\mathrm{N}_{2}$-filled glove boxes $\left(\left[\mathrm{O}_{2}\right]<1\right.$ ppm, $\left.\left[\mathrm{H}_{2} \mathrm{O}\right]<0.5 \mathrm{ppm}\right)$.

\section{RESULTS AND DISCUSSION}

Conjugated donor/acceptor copolymers comprising IDTT as the electron-rich donor unit have recently been introduced in organic photovoltaics on the merit of a good charge-transport capacity and a broad absorption spectrum that can extend into the NIR range; ${ }^{55-59}$ however, to the best of our knowledge, IDTT-based copolymers have not been developed for, nor tested in, light-emitting applications. In consideration of their potential for NIR emission and the lack of preceding studies, we have designed and synthesized a series of six donor/ acceptor alternating copolymers by combining the IDTT donor unit with one of six different acceptor units via Pd-catalyzed Stille coupling. Detailed information on the synthesis procedure can be found in the Experimental Section and is schematically presented in Figure S1. The chemical structures and the employed abbreviation of the six alternating copolymers are disclosed in Figure 1, whereas Table 1 presents modeled and 
Table 1. Physical and Electrochemical Properties of the Copolymers

\begin{tabular}{|c|c|c|c|c|c|c|}
\hline polymer & torsion (DFT) $(\varphi)^{a}$ & $E_{\mathrm{g}}(\mathrm{DFT})(\mathrm{eV})$ & $E_{\mathrm{g}}(\mathrm{OPT})^{b}(\mathrm{eV})$ & $E_{\mathrm{g}}(\mathrm{CV})(\mathrm{eV})$ & PLQY solution ${ }^{c}(\%)$ & PLQY film (\%) \\
\hline PIDTT-BT & 0.3 & 1.84 & 1.78 & 1.86 & 19 & 0.87 \\
\hline PIDTT-BTF & 0.2 & 1.84 & 1.78 & 1.83 & 29 & 0.42 \\
\hline PIDTT-Q & 6.8 & 1.99 & 1.80 & 2.04 & 26 & 1.96 \\
\hline PIDTT-QF & 7.0 & 2.01 & 1.80 & 2.10 & 34 & 2.75 \\
\hline PIDTT-TQ & 13.8 & 2.00 & 1.82 & 2.01 & 14 & 3.60 \\
\hline PIDTT-TQF & 12.3 & 1.98 & 1.82 & 2.07 & 19 & 3.59 \\
\hline
\end{tabular}

${ }^{a}$ Average dihedral angle for three repeat-unit oligomers. ${ }^{47-50} b^{b}$ Onset of absorption for film. ${ }^{c}$ Chloroform solution, $\lambda_{\text {exc }}=540 \mathrm{~nm}$; standard, Cresyl Violet in ethanol (PLQY 54\%). ${ }^{45}$
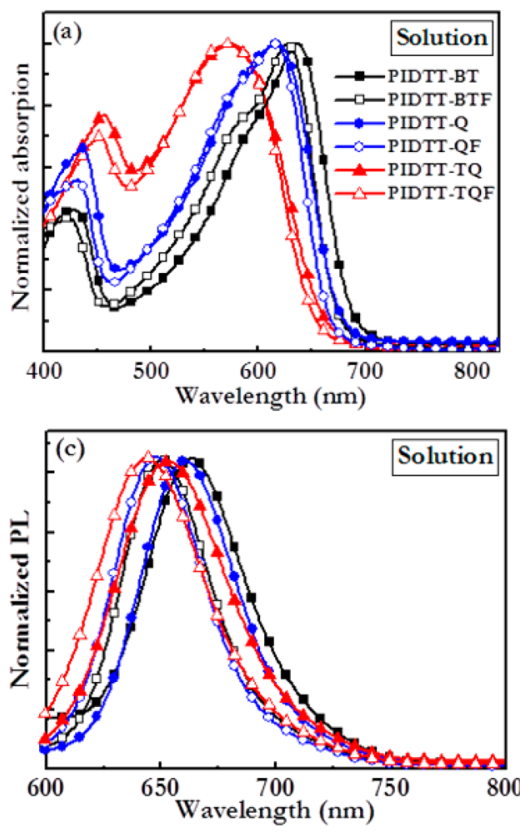
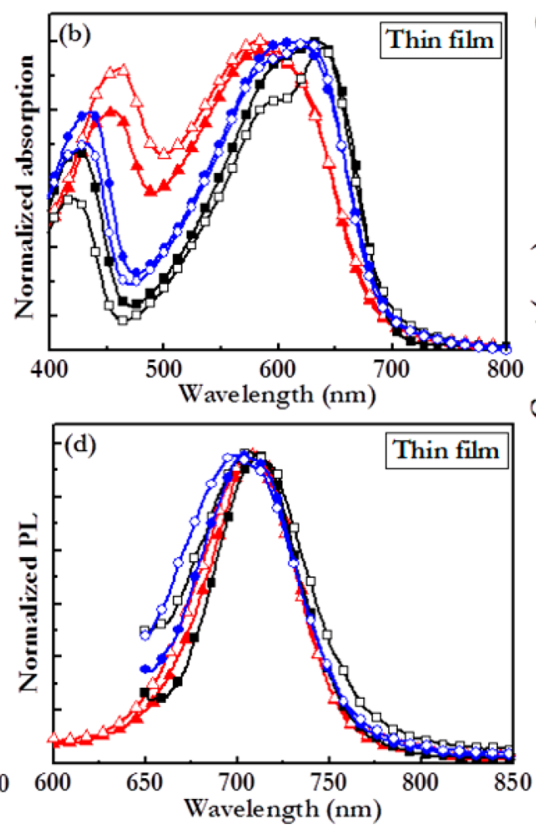

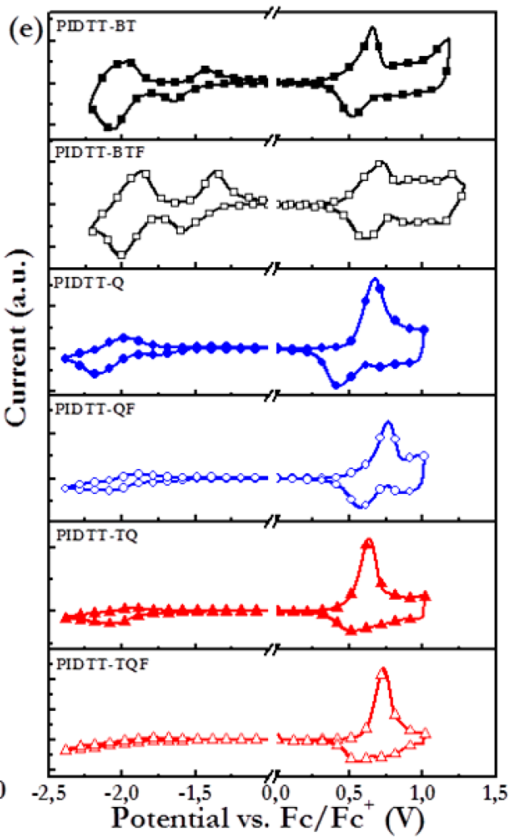

Figure 2. Absorption spectra of the copolymers in (a) dilute toluene solution (concentration $<0.001 \%$ ) and (b) as thin film (thickness $=80 \mathrm{~nm}$.) Corresponding (c) solution PL and (d) thin-film PL. (e) CV traces recorded on thin copolymer films coated on platinum wires. Scan rate $=0.1 \mathrm{~V} / \mathrm{s}$.

measured physical and electrochemical data. A TGA of three of the copolymers (PIDTT-Q PIDTT-QF, and PIDTT-TQF) is presented in Figure S6, and the measured high onset temperature for degradation $\left(T_{\text {onset }}>370{ }^{\circ} \mathrm{C}\right)$ implies that the thermal stability of the copolymers is sufficient for operation at the high current densities that are common in light-emitting devices. ${ }^{34,56,59,60}$ We note that the larger molecular-weight copolymers featured a higher molecularweight dispersion (PIDTT-BT and PIDTT-TQ) than their lower molecular-weight equivalents but emphasize that all copolymer solutions featured a sufficient viscosity for the formation of uniform and pinhole-free thin films following solution processing using spin-coating or drop-casting.

The IDTT donor unit was endowed with four bulky hexylphenyl side groups for improved solubility and for suppression of $\pi-\pi$ stacking, with the latter being motivated by the fact that $\pi-\pi$ stacking is associated with undesired luminescence quenching in related conjugated materials. ${ }^{34,35,61}$ $\mathrm{BT}^{56,60,62-64}$ and $\mathrm{BTF}^{37,55}$ are the smallest of the investigated acceptor units, and they are distinguished by the replacement of two $\mathrm{H}$ atoms with two $\mathrm{F}$ atoms in the latter; see Figure 1a. The same replacement of two $\mathrm{H}$ atoms with two $\mathrm{F}$ atoms distinguishes $\mathrm{QF}$ from $\mathrm{Q}^{34,39,40,35,65}$ (Figure 1b) and $\mathrm{TQF}^{41,43,44,61}$ from $\mathrm{TQ}^{42}$ (Figure 1c). The inclusion of electron-withdrawing $\mathrm{F}$ atoms is expected to downshift the energy structure and can in addition result in hydrogen bonding. ${ }^{55,56,58,66,67}$

The latter four acceptor units (Q, QF, TQ and TQF) comprise two bulky m-octyloxyphenyl substituents, which introduce steric conformational stress that is anticipated to result in a rotation of the polymer backbone and further suppression of $\pi-\pi$ stacking. The effect of proximity of the donor and acceptor units was investigated through the introduction of two thiophene spacing units in TQ and TQF. We have also shifted the position of the alkyl side chains on the hexylphenyl substituents on IDTT from the para position to the meta position in PIDTT-TQ and PIDTT-TQF, because previous studies on related compounds have demonstrated that this can prevent undesired polymer chain aggregation. ${ }^{68,69}$ Finally, all of the copolymers were end-capped with thiophene units, because end-capping in general has been reported to improve the charge mobility in other copolymers. ${ }^{70-72}$

We employed DFT at the B3LYP/6-31G(d,p) level ${ }^{47-50}$ to compute the minimum-energy conformation, the HOMO hole density, the LUMO electron density, and the corresponding energy gap $\left(E_{\mathrm{g}}\right)$. To save computational time, three repeat-unit oligomers with the alkyl chains replaced by methyl groups were employed as model compounds for the corresponding copolymers, and our most important findings are presented in Figure 1 and Table 1 . We find that the replacement of $\mathrm{H}$ 
with F consistently downshifts both the HOMO and LUMO energy levels by $\sim 0.1 \mathrm{eV}$, which is in line with previous results in the literature, ${ }^{41,56,73}$ but also it was not possible to discern any significant effects on neither the conformation nor the electron densities. We therefore only present the minimumenergy conformation and HOMO and LUMO densities for the $\mathrm{H}$-substituted copolymers in Figure 1, but the data for all calculated structures can be found in the Supporting Information (Figures S7-S15 and Tables S1-S6). The LUMO and HOMO of the six different copolymers are broadly similar, with the hole density spread over essentially the entire backbone, while the electron density is largely localized on the (nonterminal) acceptor sites. This agrees well with literature reports for related donor/acceptor structures. ${ }^{34,55,56,60,67,74}$

We find that the selection of the acceptor unit has a strong influence on the conformation, as visualized in the lower left panels in Figure 1 and as quantified in Table 1: the BT/BTF acceptor units result in a highly coplanar donor/acceptor conformation, the $\mathrm{Q} / \mathrm{QF}$ acceptors induce a moderate donor/ acceptor torsion angle $(\varphi)$ of $\sim 7^{\circ}$, while the largest rotation is apparent for the TQ/TQF acceptors that feature a significant $\varphi$ $=12-14^{\circ}$. We attribute the conformational rotation to the steric hindrance introduced by the addition of bulky $m$ octyloxyphenyl substituents onto the acceptor units. We also conclude that the introduction of the thiophene spacer units between the donor and acceptor and the para-to-meta attachment shift of the hexylphenyl substituents on the donor in the TQ/TQF-based molecules facilitate for an even more twisted conformation. The latter conclusion is supported by a dedicated DFT study that reveals that an increased backbone rotation is attained by either of the two changes but that the most twisted conformation is achieved only when both changes have been implemented (see Figures S16 and S17 and Table 1).

Parts $\mathrm{a}$ and $\mathrm{b}$ of Figure 2 present the absorption spectra for the different copolymers in solution and as a solid thin film, respectively. The absorption and PL data were normalized to facilitate for observation of the relatively minor changes, but the non-normalized thin-film absorption data are presented in Figure S18 in order to provide quantitative information on the absorption properties of the different copolymers. In both states, the copolymers display a broad absorption profile spanning the entire visible range, with a higher-energy band at $350-450 \mathrm{~nm}$ and a lower-energy band at 500-700 $\mathrm{nm}$. The addition of $\mathrm{F}$ atoms to the acceptor unit has in general a negligible influence on the absorption profile, with the minor exception being that the PIDTT-BTF spectrum is bit more structured than the corresponding PIDTT-BT spectrum. This could be an indicator of increased ordering through the emergence of hydrogen bonding. We further find that the major absorption peak of the PIDTT-BT/PIDTT-BTF pair is slightly red-shifted, while PIDTT-TQ/PIDTT-TQF is blueshifted, with respect to the PIDTT-Q/PIDTT-QF. We calculated the optical energy gap, $E_{\mathrm{g}}$ (OPT), as the onset of absorption for the thin films, and the data are presented in Table 1.

The solution and thin-film PL spectra of the copolymers are presented in parts $\mathrm{c}$ and $\mathrm{d}$ of Figure 2, respectively. All copolymers feature a broad and structureless PL envelope in both solution and solid state, but the PIDTT-BT and PIDTTQ polymers are distinguished by a slightly red-shifted emission in solution. Importantly, although we did not observe signs of strong aggregation even in concentrated solution (see Figure
S19), the general trend of a distinct red-shift of the PL spectrum by $\sim 50 \mathrm{~nm}$ in going from solution (Figure $2 \mathrm{c}$ ) to solid state (Figure $2 \mathrm{~d}$ ) implies that $\pi-\pi$ stacking/aggregation is common in the solid state. We note that this conclusion is consistent with the planar molecular conformations derived from the DFT calculations (see Figure 1).

The PLQY data for the copolymers in dilute chloroform solution and as a solid thin film are presented in Table 1 . The highest PLQY value in solution was $34 \%$ for PIDTT-QF, and the trend is that the F-substituted copolymers feature a higher solution PLQY than the H-substituted copolymers. We note that the PLQY drops drastically in going from solution to solid thin film, which suggests that aggregation-induced luminance quenching is prominent in the solid thin films. The highest PLQY value in the solid state is $3.6 \%$ for the PIDTT-TQ/ PIDTT-TQF pair. We further note with interest that the relative change in PLQY in going from solution to thin film is largest for PIDTT-BT/PIDTT-BTF and smallest for PIDTTTQ/PIDTT-TQF, which is in agreement with the fact that the aggregation-induced quenching increases with increasing planarity of the copolymer conformation (see DFT data in Figure 1 and Table 1).

The electrochemical properties of the copolymer films were investigated with CV. Figure 2e discloses that all copolymers exhibit strong and reversible or semireversible electrochemical p-type doping (or oxidation), while the electrochemical n-type doping (reduction) capacity varies markedly. The PIDTT-BT/ PIDTT-BTF pair features the most balanced p-type and n-type doping, while the relative capacity for n-type doping is markedly weaker for the PIDTT-TQ/PIDTT-TQF pair. We also note that the n-type doping capacity appears to be lower for the F-substituted copolymers than for their H-substituted counterparts. The dependence of the n-type doping capacity on acceptor selection is in good qualitative agreement with the DFT electron-density data in Figure 1, which demonstrated that the LUMO is mainly located on the acceptor sites and that the n-type doping (reduction) accordingly should be dependent on acceptor selection. The $E_{\mathrm{g}}$ derived from the $\mathrm{CV}$ data are essentially identical to those calculated by DFT (see Table 1), while the $E_{\mathrm{g}}$ derived from the absorption onset data are a bit lower, particularly for the larger-gap copolymers. Nevertheless, the overall trend from both DFT, absorption, and $\mathrm{CV}$ is that the PIDTT-BT/PIDTT-BTF pair features the lowest $E_{g}$, which is a desirable property for long-wavelength NIR applications.

We now turn our attention to the study of the performance of the NIR copolymers in LEC devices. The optimized device structure comprised a blend of the NIR copolymer and a $\mathrm{THABF}_{4}$ ionic liquid in a 10:1 mass ratio as the $80 \mathrm{~nm}$ thick active material sandwiched between an $\mathrm{Al}$ cathode and an ITO/ PEDOT:PSS anode. The concentration of ionic liquid was selected so that the average doping concentration in the $\mathrm{p}$ - and n-type doped regions at steady state is $0.7-1.0$ dopants/ copolymer repeat unit, as calculated with the procedure outlined in ref 75 . We have also tested other electrolytes, such as the salt $\mathrm{LiCF}_{3} \mathrm{SO}_{3}$ dissolved in hydroxyl-capped trimethylolpropaneethoxylate, ${ }^{76}$ but the best results were obtained with $\mathrm{THABF}_{4}$. For efficient and stable LEC operation, it is fundamental that the electrolyte is electrochemically inert during the p-type and n-type doping of the electroactive compound, here being the copolymer. ${ }^{97}$ Figure S20 presents the p-type and n-type doping potentials of the six different copolymers (solid lines) and the electrochemical stability window of the electrolyte (dashed line). It is clear that all 

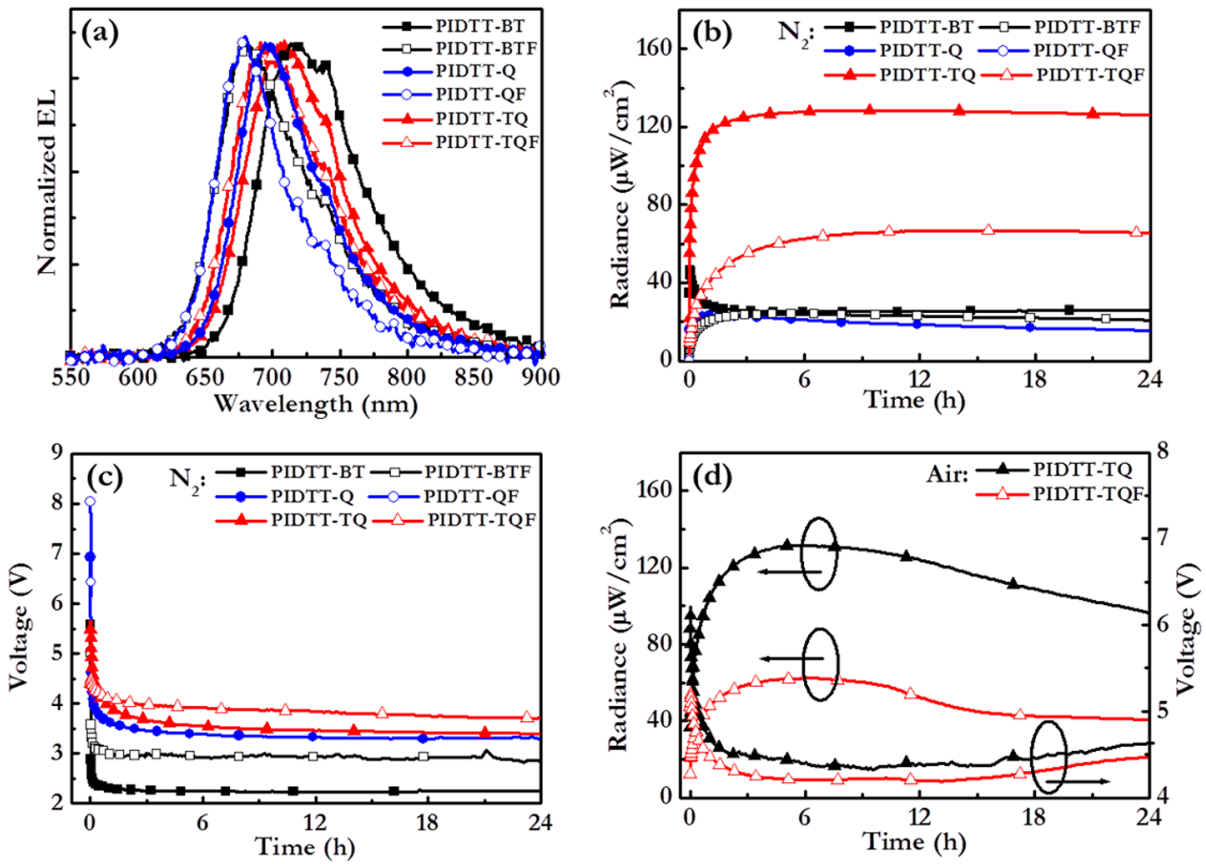

Figure 3. (a) EL spectra of the ITO/PEDOT:PSS/copolymer:THABF 4 /Al NIR-LECs during steady-state operation. Temporal evolution of (b) the radiance and (c) the voltage of the NIR-LECs during operation under $\mathrm{N}_{2}$ atmosphere. (d) Optoelectronic performance of nonencapsulated NIRLECs during operation under ambient air. All devices were driven with a constant current density of $j=74.5 \mathrm{~mA} / \mathrm{cm}^{2}$.

copolymers can be electrochemically $\mathrm{p}$ - and n-type doped without any interference from electrolyte-induced side reactions.

Figure 3a presents the normalized electroluminescence (EL) spectra of the different NIR-LECs. The EL peaks are positioned between 681 and $706 \mathrm{~nm}$ and are slightly blue-shifted by 5-25 $\mathrm{nm}$ with respect to their corresponding thin-film PL peaks, as presented in Figure 2d. We note that the EL peaks from the Fsubstituted copolymers are blue-shifted by $\sim 20 \mathrm{~nm}$ in comparison to their $\mathrm{H}$-substituted counterparts (see also Table 2). The temporal evolution of the radiance and voltage

\section{Table 2. NIR-LEC Device Performance}

\begin{tabular}{|c|c|c|c|c|c|}
\hline copolymer & $\begin{array}{c}\text { EL } \\
\text { peak } \\
(\mathrm{nm})\end{array}$ & $\begin{array}{c}\text { peak } \\
\text { radiance } \\
\left(\mu \mathrm{W} / \mathrm{cm}^{2}\right)\end{array}$ & EQE (\%) & $\begin{array}{l}\text { peak power } \\
\text { efficiency } \\
(\mathrm{mW} / \mathrm{W})\end{array}$ & $\begin{array}{c}X_{\text {ideal }} \text { (the } \\
\text { ideality } \\
\text { factor) }\end{array}$ \\
\hline $\begin{array}{l}\text { PIDTT- } \\
\text { BT }\end{array}$ & 706 & 47 & 0.038 & 0.24 & 0.88 \\
\hline $\begin{array}{l}\text { PIDTT- } \\
\text { BTF }\end{array}$ & 681 & 24 & 0.018 & 0.11 & 0.85 \\
\hline PIDTT-Q & 695 & 23 & 0.018 & 0.092 & 0.18 \\
\hline $\begin{array}{l}\text { PIDTT- } \\
\text { QF }\end{array}$ & 679 & 16 & 0.009 & 0.025 & 0.07 \\
\hline $\begin{array}{l}\text { PIDTT- } \\
\text { TQ }\end{array}$ & 705 & 129 & 0.10 & 0.48 & 0.56 \\
\hline $\begin{array}{l}\text { PIDTT- } \\
\text { TQF }\end{array}$ & 690 & 67 & 0.050 & 0.28 & 0.28 \\
\hline
\end{tabular}

of the NIR-LECs during driving with a constant-current density of $j=74.5 \mathrm{~mA} / \mathrm{cm}^{2}$ is displayed in parts b and $\mathrm{c}$ of Figure 3, respectively. We find that all NIR-LECs display a well-behaved LEC operation, with an increase of the radiance and a lowering of the voltage with time during the initial turn-on process when the $\mathrm{p}-\mathrm{n}$ junction doping structure forms in the active material. This is consistent with the fact that all copolymers can be both p-type and n-type doped, as well as that the other device constituents are electrochemically stable.
The PIDTT-TQ and PIDTT-TQF copolymers deliver the best performance in LEC devices, with the PIDTT-TQ-based LEC featuring a peak radiance of $129 \mu \mathrm{W} / \mathrm{cm}^{2}$ at a quantum efficiency of $0.10 \%$ and a power efficiency of $0.24 \mathrm{~mW} / \mathrm{W}$ (Table 2). This radiance was delivered at an EL peak wavelength of $705 \mathrm{~nm}$ and a steady-state driving voltage of $3.4 \mathrm{~V}$. To the best of our knowledge, this is the highest radiance for a metal-free NIR-LEC driven by a constant bias to date.

The corresponding device-performance data for the other copolymers are summarized in Table 2 . We observe that the $\mathrm{H}$ substituted copolymers invariably deliver a higher performance in LEC devices than their F-substituted counterparts, despite the fact that the PLQY in the solid state was found to be relatively independent of the $\mathrm{H}$ - or F-substitution (see Table 1). To shed further light on this issue, we prepared and fabricated OLED devices, void of the electrolyte and with $\mathrm{Ca}$ instead of $\mathrm{Al}$ as the cathode, based on the two best-performing copolymers (PIDTT-TQ and PIDTT-TQF); their device performance is summarized in Table S7. Interestingly, we find that the fluorinated copolymer performs better in the OLED device, which implies that the observed opposite trend in the LEC device is specific to LECs. At this stage, we tentatively attribute this deviating behavior in LEC devices to the more hydrophilic character of the F-substituted copolymers, which makes blending with the hydrophobic $\mathrm{THABF}_{4}$ electrolyte difficult, and to the more compact morphology induced by the hydrogen bonding in the F-substituted copolymers, which makes the ion ingress during doping difficult.

We also wish to call attention to the good device stability, as presented in Figure $3 \mathrm{~b}-\mathrm{d}$. We find that the radiance for the PIDTT-TQ/PIDTT-TQF-based LECs is essentially intact (dropped by $\sim 3 \%$ ) following 1 day of continuous operation under $\mathrm{N}_{2}$ atmosphere (Figure $3 \mathrm{~b}$ ). Even more noteworthy, the radiance output from the corresponding nonencapsulated LECs only dropped by $\sim 27 \%$ following 1 day of continuous 
operation under ambient air, as displayed in Figure $3 \mathrm{~d}$ and summarized in Table S8.

It is educational for the future design and synthesis of improved NIR emitters to evaluate the bottlenecks in the current LEC performance. The external quantum efficiency (EQE) can be described by the following equation,

$$
\mathrm{EQE}=\eta_{\mathrm{Rec}} \times \eta_{\mathrm{ST}} \times \eta_{\mathrm{PLQY}} \times \eta_{\mathrm{Out}} \times X_{\text {Ideal }}
$$

where $\eta_{\mathrm{Rec}}$ is the ratio of the number of exciton formation events within the device to the number of electrons flowing in the external circuit, $\eta_{\mathrm{ST}}$ is the fraction of excitons that are formed as singlets, $\eta_{\mathrm{PLQY}}$ is the PLQY of the emitter, $\eta_{\text {Out }}$ is the out-coupling efficiency of the device structure, and $X_{\text {Ideal }}$ is an ideality factor that represents the combined additional loss mechanisms due to, e.g., exciton-polaron, ${ }^{78,79}$ exciton-exciton, and exciton-electrode quenching. The latter is thus an indicator of the quality of the $\mathrm{p}-\mathrm{n}$ junction doping structure for efficient light emission. The measured values for EQE are tabulated in Table 2, while $\eta_{\mathrm{Rec}}$ and $\eta_{\mathrm{ST}}$ are set to 1 and 0.25 , respectively, in consideration of the effective electron-hole recombination in a $\mathrm{p}-\mathrm{n}$ homojunction and the generic singlettriplet branching ratio in organic conjugated polymers. The measured values for $\eta_{\mathrm{PLQY}}$ of the copolymer films are tabulated in Table 1 , while the value for $\eta_{\text {Out }}$ is estimated to be $\sim 0.2$ following the procedure outlined in refs 80 and 81, assuming a value for the refractive index of the copolymers of 1.5 . With this information at hand, the ideality factor $X_{\text {Ideal }}$ can be calculated, and the values for the different copolymers are summarized in Table 2.

Interestingly, the highest radiance and EQE values were obtained with the PIDTT-TQ/PIDTT-TQF pair, but the highest ideality factor was attained for devices comprising PIDTT-BT/PIDTT-BTF as the emitter. It is notable that the latter two copolymers featured the most balanced $\mathrm{p}$ - and n-type doping capacity in the CV measurements (Figure 2e), as balanced p- and n-type doping can be anticipated to result in a centered $\mathrm{p}-\mathrm{n}$ junction in LEC devices, ${ }^{82}$ with a concomitant suppression of the undesired quenching of excitons by metal electrodes and polarons. ${ }^{77,78}$ The same argument of a more balanced $\mathrm{p}$ - and n-type doping capacity can explain the higher value for $X_{\text {Ideal }}$ for the $H$-substituted copolymers over their Fsubstituted counterparts (see Figure 2e and Table 2). A summarizing design guideline for a future synthesis of NIRemitting polymers fit for efficient LEC operation would then include the following: (i) high PLQY in solution, (ii) suppression of aggregation in the solid state for a retained high PLQY in thin films, (iii) use of nonfluorinated materials for good compatibility with the electrolyte and for facile and balanced doping reactions, and (iv) selection of donor and acceptor units that deliver balanced $\mathrm{p}$ - and n-type doping.

\section{CONCLUSIONS}

We report on the synthesis and characterization of a group of systematically designed IDTT-based donor/acceptor copolymers for application in NIR-emitting LEC devices with airstable electrodes. We demonstrate that the selection of the acceptor unit strongly affects the PLQY in both solution and the solid state, the aggregation in the solid state, and the electrochemical doping capacity. All of these factors have a direct influence on the LEC device performance, and we are able to establish rational guidelines for the design of further improved NIR-emitting donor/acceptor copolymers. Never- theless, the best performing NIR-LEC device within this study was based on the PIDTT-TQ copolymer, and it delivered a record-high radiance of $129 \mu \mathrm{W} / \mathrm{cm}^{2}$ at an emission peak at $705 \mathrm{~nm}$ and at a low drive voltage of $3.4 \mathrm{~V}$. The NIR-LEC also featured surprisingly good operational stability in the nonencapsulated state. This work thus introduces IDTT-based donor/acceptor copolymers as functional metal-free NIRemitting materials for application in low-cost devices with attractive form factors.

\section{ASSOCIATED CONTENT}

\section{S Supporting Information}

The Supporting Information is available free of charge on the ACS Publications website at DOI: 10.1021/acs.chemmater.7b02049.

Synthesis and characterization, ${ }^{1} \mathrm{H}$ NMR spectra, TGA measurements, DFT calculation, and optical properties (PDF)

\section{AUTHOR INFORMATION}

\section{Corresponding Authors}

*ergang@chalmers.se.

*ludvig.edman@umu.se.

ORCID *

Ludvig Edman: 0000-0003-2495-7037

Author Contributions

${ }^{\perp}$ S.T. and P.M. contributed equally to this work.

\section{Notes}

The authors declare no competing financial interest.

\section{ACKNOWLEDGMENTS}

The authors acknowledge financial support from the Swedish Foundation for Strategic Research, the Swedish Research Council, the Swedish Energy Agency, Kempestiftelserna, the Knut and Alice Wallenberg Foundation, and the European Community's Seventh Framework Programme (FP7/20072013) under Grant Agreement no. 607585 (OSNIRO).

\section{REFERENCES}

(1) Shanmugam, V.; Selvakumar, S.; Yeh, C.-S. Near-infrared lightresponsive nanomaterials in cancer therapeutics. Chem. Soc. Rev. 2014, 43 (17), 6254-6287.

(2) Chen, Z.; Zhang, L.; Sun, Y.; Hu, J.; Wang, D. 980-nm LaserDriven Photovoltaic Cells Based on Rare-Earth Up-Converting Phosphors for Biomedical Applications. Adv. Funct. Mater. 2009, 19 (23), 3815-3820.

(3) Heerlein, J.; Behringer, M.; Jäger, C. Near-infrared power LED for emerging security and defence applications. Proc. SPIE 8186, Electro-Optical Remote Sensing, Photonic Technologies, and Applications $V$; SPIE Security + Defence, Prague, Czech Republic, 2011; SPIE: 2011; p 81860O.

(4) Tessler, N.; Medvedev, V.; Kazes, M.; Kan, S.; Banin, U. Efficient Near-Infrared Polymer Nanocrystal Light-Emitting Diodes. Science 2002, 295 (5559), 1506-1508.

(5) Haigh, P. A.; Bausi, F.; Ghassemlooy, Z.; Papakonstantinou, I.; Le Minh, H.; Fléchon, C.; Cacialli, F. Visible light communications: real time $10 \mathrm{Mb} / \mathrm{s}$ link with a low bandwidth polymer light-emitting diode. Opt. Express 2014, 22 (3), 2830-2838.

(6) Cocchi, M.; Kalinowski, J.; Virgili, D.; Williams, J. A. G. Excimerbased red/near-infrared organic light-emitting diodes with very high quantum efficiency. Appl. Phys. Lett. 2008, 92 (11), 113302. 
(7) Cocchi, M.; Virgili, D.; Fattori, V.; Williams, J. A. G.; Kalinowski, J. Highly efficient near-infrared organic excimer electrophosphorescent diodes. Appl. Phys. Lett. 2007, 90 (2), 023506.

(8) Tuong Ly, K.; Chen-Cheng, R.-W.; Lin, H.-W.; Shiau, Y.-J.; Liu, S.-H.; Chou, P.-T.; Tsao, C.-S.; Huang, Y.-C.; Chi, Y. Near-infrared organic light-emitting diodes with very high external quantum efficiency and radiance. Nat. Photonics 2017, 11 (1), 63-68.

(9) Gong, X.; Yang, Z.; Walters, G.; Comin, R.; Ning, Z.; Beauregard, E.; Adinolfi, V.; Voznyy, O.; Sargent, E. H. Highly efficient quantum dot near-infrared light-emitting diodes. Nat. Photonics 2016, 10 (4), 253-257.

(10) Wang, S.; Yan, X.; Cheng, Z.; Zhang, H.; Liu, Y.; Wang, Y. Highly Efficient Near-Infrared Delayed Fluorescence Organic Light Emitting Diodes Using a Phenanthrene-Based Charge-Transfer Compound. Angew. Chem., Int. Ed. 2015, 54 (44), 13068-13072.

(11) Borek, C.; Hanson, K.; Djurovich, P. I.; Thompson, M. E.; Aznavour, K.; Bau, R.; Sun, Y.; Forrest, S. R.; Brooks, J.; Michalski, L.; Brown, J. Highly Efficient, Near-Infrared Electrophosphorescence from a Pt-Metalloporphyrin Complex. Angew. Chem., Int. Ed. 2007, 46 (7), 1109-1112.

(12) Xue, J.; Li, C.; Xin, L.; Duan, L.; Qiao, J. High-efficiency and low efficiency roll-off near-infrared fluorescent OLEDs through triplet fusion. Chem. Sci. 2016, 7 (4), 2888-2895.

(13) Yao, L.; Zhang, S.; Wang, R.; Li, W.; Shen, F.; Yang, B.; Ma, Y. Highly Efficient Near-Infrared Organic Light-Emitting Diode Based on a Butterfly-Shaped Donor-Acceptor Chromophore with Strong SolidState Fluorescence and a Large Proportion of Radiative Excitons. Angew. Chem. Int. Ed. 2014, 53 (8), 2119-2123.

(14) Graham, K. R.; Yang, Y.; Sommer, J. R.; Shelton, A. H.; Schanze, K. S.; Xue, J.; Reynolds, J. R. Extended Conjugation Platinum(II) Porphyrins for use in Near-Infrared Emitting Organic Light Emitting Diodes. Chem. Mater. 2011, 23 (24), 5305-5312.

(15) Rosenow, T. C.; Walzer, K.; Leo, K. Near-infrared organic light emitting diodes based on heavy metal phthalocyanines. J. Appl. Phys. 2008, 103 (4), 043105.

(16) Qian, G.; Zhong, Z.; Luo, M.; Yu, D.; Zhang, Z.; Wang, Z. Y.; Ma, D. Simple and Efficient Near-Infrared Organic Chromophores for Light-Emitting Diodes with Single Electroluminescent Emission above $1000 \mathrm{~nm}$. Adv. Mater. 2009, 21 (1), 111-116.

(17) Pei, Q. B.; Yu, G.; Zhang, C.; Yang, Y.; Heeger, A. J. Polymer Light-Emitting Electrochemical-Cells. Science 1995, 269 (5227), 1086-1088.

(18) Matyba, P.; Yamaguchi, H.; Eda, G.; Chhowalla, M.; Edman, L.; Robinson, N. D. Graphene and Mobile Ions: The Key to All-Plastic, Solution-Processed Light-Emitting Devices. ACS Nano 2010, 4 (2), 637-642.

(19) Sandström, A.; Dam, H. F.; Krebs, F. C.; Edman, L. Ambient fabrication of flexible and large-area organic light-emitting devices using slot-die coating. Nat. Commun. 2012, 3, 1002.

(20) Sandström, A.; Asadpoordarvish, A.; Enevold, J.; Edman, L. Spraying Light: Ambient-Air Fabrication of Large-Area Emissive Devices on Complex-Shaped Surfaces. Adv. Mater. 2014, 26 (29), 4975-4980.

(21) Zhang, Z.; Guo, K.; Li, Y.; Li, X.; Guan, G.; Li, H.; Luo, Y.; Zhao, F.; Zhang, Q.; Wei, B.; Pei, Q.; Peng, H. A colour-tunable, weavable fibre-shaped polymer light-emitting electrochemical cell. Nat. Photonics 2015, 9 (4), 233-238.

(22) Mindemark, J.; Tang, S.; Wang, J.; Kaihovirta, N.; Brandell, D.; Edman, L. High-Performance Light-Emitting Electrochemical Cells by Electrolyte Design. Chem. Mater. 2016, 28 (8), 2618-2623.

(23) Hernandez-Sosa, G.; Tekoglu, S.; Stolz, S.; Eckstein, R.; Teusch, C.; Trapp, J.; Lemmer, U.; Hamburger, M.; Mechau, N. The Compromises of Printing Organic Electronics: A Case Study of Gravure-Printed Light-Emitting Electrochemical Cells. Adv. Mater. 2014, 26 (20), 3235-3240.

(24) Namanga, J. E.; Gerlitzki, N.; Mudring, A.-V. Scrutinizing Design Principles toward Efficient, Long-Term Stable Green LightEmitting Electrochemical Cells. Adv. Funct. Mater. 2017, 27, 1605588.
(25) Wang, S.; Li, X.; Xun, S.; Wan, X.; Wang, Z. Y. Near-Infrared Electrochromic and Electroluminescent Polymers Containing Pendant Ruthenium Complex Groups. Macromolecules 2006, 39 (22), 75027507.

(26) Bolink, H. J.; Coronado, E.; Costa, R. D.; Gaviña, P.; Ortí, E.; Tatay, S. Deep-Red-Emitting Electrochemical Cells Based on Heteroleptic Bis-chelated Ruthenium(II) Complexes. Inorg. Chem. 2009, 48 (9), 3907-3909.

(27) Bolink, H. J.; Cappelli, L.; Coronado, E.; Gaviña, P. Observation of Electroluminescence at Room Temperature from a Ruthenium(II) Bis-Terpyridine Complex and Its Use for Preparing Light-Emitting Electrochemical Cells. Inorg. Chem. 2005, 44 (17), 5966-5968.

(28) Bideh, B. N.; Roldan-Carmona, C.; Shahroosvand, H.; Nazeeruddin, M. K. Ruthenium Phenanthroimidazole complexes for Near Infrared Light-Emitting Electrochemical Cell. J. Mater. Chem. C 2016, 4 (44), 9674-9679.

(29) Zhong, C.; Duan, C.; Huang, F.; Wu, H.; Cao, Y. Materials and Devices toward Fully Solution Processable Organic Light-Emitting Diodes. Chem. Mater. 2011, 23 (3), 326-340.

(30) Lee, C.-L.; Cheng, C.-Y.; Su, H.-C. Enhancing device efficiencies of solid-state near-infrared light-emitting electrochemical cells by employing a tandem device structure. Org. Electron. 2014, 15 (3), 711-720.

(31) Hsu, J.-H.; Su, H.-C. Host-only solid-state near-infrared lightemitting electrochemical cells based on interferometric spectral tailoring. Phys. Chem. Chem. Phys. 2016, 18 (6), 5034-5039.

(32) Pertegás, A.; Tordera, D.; Serrano-Pérez, J. J.; Ortí, E.; Bolink, H. J. Light-Emitting Electrochemical Cells Using Cyanine Dyes as the Active Components. J. Am. Chem. Soc. 2013, 135 (48), 18008-18011.

(33) Larsen, C.; Forchheimer, R.; Edman, L.; Tu, D. Design, fabrication and application of organic power converters: Driving lightemitting electrochemical cells from the AC mains. Org. Electron. 2017, $45,57-64$

(34) Xu, X.; Cai, P.; Lu, Y.; Choon, N. S.; Chen, J.; Ong, B. S.; Hu, X. Synthesis of a novel low-bandgap polymer based on a ladder-type Heptacyclic arene consisting of outer thieno[3,2-b]thiophene units for efficient photovoltaic application. Macromol. Rapid Commun. 2013, 34 (8), 681-688.

(35) Xu, X.; Li, Z.; Bäcke, O.; Bini, K.; James, D. I.; Olsson, E.; Andersson, M. R.; Wang, E. Effects of side chain isomerism on the physical and photovoltaic properties of indacenodithieno[3,2-b]thiophene-quinoxaline copolymers: toward a side chain design for enhanced photovoltaic performance. J. Mater. Chem. A 2014, 2 (44), 18988-18997.

(36) Zoombelt, A. P.; Fonrodona, M.; Turbiez, M. G. R.; Wienk, M. M.; Janssen, R. A. J. Synthesis and photovoltaic performance of a series of small band gap polymers. J. Mater. Chem. 2009, 19 (30), 53365342.

(37) Zhang, Y.; Chien, S.-C.; Chen, K.-S.; Yip, H.-L.; Sun, Y.; Davies, J. A.; Chen, F.-C.; Jen, A. K.-Y. Increased open circuit voltage in fluorinated benzothiadiazole-based alternating conjugated polymers. Chem. Commun. 2011, 47 (39), 11026-11028.

(38) Dou, L.; Chen, C.-C.; Yoshimura, K.; Ohya, K.; Chang, W.-H.; Gao, J.; Liu, Y.; Richard, E.; Yang, Y. Synthesis of 5H-Dithieno[3,2b:2,3-d]pyran as an Electron-Rich Building Block for Donor-Acceptor Type Low-Bandgap Polymers. Macromolecules 2013, 46 (9), 33843390.

(39) Gadisa, A.; Mammo, W.; Andersson, L. M.; Admassie, S.; Zhang, F.; Andersson, M. R.; Inganäs, O. A New Donor-Acceptor-Donor Polyfluorene Copolymer with Balanced Electron and Hole Mobility. Adv. Funct. Mater. 2007, 17 (18), 3836-3842.

(40) Wang, E.; Hou, L.; Wang, Z.; Hellstrom, S.; Zhang, F.; Inganas, O.; Andersson, M. R. An easily synthesized blue polymer for highperformance polymer solar cells. Adv. Mater. 2010, 22 (46), 52405244.

(41) Dang, D.; Chen, W.; Yang, R.; Zhu, W.; Mammo, W.; Wang, E. Fluorine substitution enhanced photovoltaic performance of a D-A1D-A2 copolymer. Chem. Commun. 2013, 49 (81), 9335-9337. 
(42) Gedefaw, D.; Zhou, Y.; Hellström, S.; Lindgren, L.; Andersson, L. M.; Zhang, F.; Mammo, W.; Inganäs, O.; Andersson, M. R. Alternating copolymers of fluorene and donor-acceptor-donor segments designed for miscibility in bulk heterojunction photovoltaics. J. Mater. Chem. 2009, 19 (30), 5359-5363.

(43) Bolognesi, M.; Gedefaw, D.; Dang, D.; Henriksson, P.; Zhuang, W.; Tessarolo, M.; Wang, E.; Muccini, M.; Seri, M.; Andersson, M. R. 2D $\pi$-conjugated benzo[1,2-b:4,5-b]dithiophene- and quinoxalinebased copolymers for photovoltaic applications. RSC Adv. 2013, 3 (46), 24543-24552.

(44) Gedefaw, D.; Tessarolo, M.; Zhuang, W.; Kroon, R.; Wang, E.; Bolognesi, M.; Seri, M.; Muccini, M.; Andersson, M. R. Conjugated polymers based on benzodithiophene and fluorinated quinoxaline for bulk heterojunction solar cells: thiophene versus thieno[3,2-b]thiophene as $\pi$-conjugated spacers. Polym. Chem. 2014, 5 (6), 2083-2093.

(45) Magde, D.; Brannon, J. H.; Cremers, T. L.; Olmsted, J. Absolute luminescence yield of cresyl violet. A standard for the red. J. Phys. Chem. 1979, 83 (6), 696-699.

(46) Frisch, M. J.; Trucks, G. W.; Schlegel, H. B.; Scuseria, G. E.; Robb, M. A.; Cheeseman, J. R.; Scalmani, G.; Barone, V.; Mennucci, B.; Petersson, G. A.; Nakatsuji, H.; Caricato, M.; Li, X.; Hratchian, H. P.; Izmaylov, A. F.; Bloino, J.; Zheng, G.; Sonnenberg, J. L.; Hada, M.; Ehara, M.; Toyota, K.; Fukuda, R.; Hasegawa, J.; Ishida, M.; Nakajima, T.; Honda, Y.; Kitao, O.; Nakai, H.; Vreven, T.; J. A. Montgomery, J.; Peralta, J. E.; Ogliaro, F.; Bearpark, M.; Heyd, J. J.; Brothers, E.; Kudin, K. N.; Staroverov, V. N.; Keith, T.; Kobayashi, R.; Normand, J.; Raghavachari, K.; Rendell, A.; Burant, J. C.; Iyengar, S. S.; Tomasi, J.; Cossi, M.; Rega, N.; Millam, J. M.; Klene, M.; Knox, J. E.; Cross, J. B.; Bakken, V.; Adamo, C.; Jaramillo, J.; Gomperts, R.; Stratmann, R. E.; Yazyev, O.; Austin, A. J.; Cammi, R.; Pomelli, C.; Ochterski, J. W.; Martin, R. L.; Morokuma, K.; Zakrzewski, V. G.; Voth, G. A.; Salvador, P.; Dannenberg, J. J.; Dapprich, S.; Daniels, A. D.; Farkas, O.; Foresman, J. B.; Ortiz, J. V.; Cioslowski, J.; Fox, D. J. Gaussian 09, Revision B.01; Gaussian, Inc.: Wallingford, CT, 2010.

(47) Hehre, W. J.; Ditchfield, R.; Pople, J. A. Self-Consistent Molecular Orbital Methods. XII. Further Extensions of Gaussian-Type Basis Sets for Use in Molecular Orbital Studies of Organic Molecules. J. Chem. Phys. 1972, 56 (5), 2257-2261.

(48) Perdew, J. P.; Wang, Y. Accurate and simple analytic representation of the electron-gas correlation energy. Phys. Rev. B: Condens. Matter Mater. Phys. 1992, 45 (23), 13244-13249.

(49) Becke, A. D. Density-functional thermochemistry. III. The role of exact exchange. J. Chem. Phys. 1993, 98 (7), 5648-5652.

(50) Cohen, A. J.; Mori-Sanchez, P.; Yang, W. Challenges for density functional theory. Chem. Rev. 2012, 112 (1), 289-320.

(51) Brédas, J.-L. Organic Electronics: Does a Plot of the HOMOLUMO Wave Functions Provide Useful Information? Chem. Mater. 2017, 29 (2), 477-478.

(52) Liu, S.; Kan, Z.; Thomas, S.; Cruciani, F.; Brédas, J.-L.; Beaujuge, P. M. Thieno[3,4-c]pyrrole-4,6-dione-3,4-difluorothiophene Polymer Acceptors for Efficient All-Polymer Bulk Heterojunction Solar Cells. Angew. Chem., Int. Ed. 2016, 55 (42), 12996-13000.

(53) Liu, S.; Song, X.; Thomas, S.; Kan, Z.; Cruciani, F.; Laquai, F.; Brédas, J.-L.; Beaujuge, P. M. Thieno[3,4-c]Pyrrole-4,6-Dione-Based Polymer Acceptors for High Open-Circuit Voltage All-Polymer Solar Cells. Adv. Energy Mater. 2017, 7, 1602574.

(54) Chai, J.-D.; Head-Gordon, M. Long-range corrected hybrid density functionals with damped atom-atom dispersion corrections. Phys. Chem. Chem. Phys. 2008, 10 (44), 6615-6620.

(55) Xu, Y.-X.; Chueh, C.-C.; Yip, H.-L.; Ding, F.-Z.; Li, Y.-X.; Li, C.Z.; Li, X.; Chen, W.-C.; Jen, A. K.-Y. Improved charge transport and absorption coefficient in indacenodithieno[3,2-b]thiophene-based ladder-type polymer leading to highly efficient polymer solar cells. Adv. Mater. 2012, 24 (47), 6356-6361.

(56) Chang, H.-H.; Tsai, C.-E.; Lai, Y.-Y.; Chiou, D.-Y.; Hsu, S.-L.; Hsu, C.-S.; Cheng, Y.-J. Synthesis, Molecular and Photovoltaic Properties of Donor-Acceptor Conjugated Polymers Incorporating a New Heptacylic Indacenodithieno[3,2-b]thiophene Arene. Macromolecules 2012, 45 (23), 9282-9291.

(57) Xu, Y.-X.; Chueh, C.-C.; Yip, H.-L.; Chang, C.-Y.; Liang, P.-W.; Intemann, J. J.; Chen, W.-C.; Jen, A. K.-Y. Indacenodithieno[3,2b]thiophene-based broad bandgap polymers for high efficiency polymer solar cells. Polym. Chem. 2013, 4 (20), 5220-5223.

(58) Intemann, J. J.; Yao, K.; Li, Y.-X.; Yip, H.-L.; Xu, Y.-X.; Liang, P.W.; Chueh, C.-C.; Ding, F.-Z.; Yang, X.; Li, X.; Chen, Y.; Jen, A. K.-Y. Highly Efficient Inverted Organic Solar Cells Through Material and Interfacial Engineering of Indacenodithieno[3,2-b]thiophene-Based Polymers and Devices. Adv. Funct. Mater. 2014, 24 (10), 1465-1473.

(59) Gasparini, N.; Katsouras, A.; Prodromidis, M. I.; Avgeropoulos, A.; Baran, D.; Salvador, M.; Fladischer, S.; Spiecker, E.; Chochos, C. L.; Ameri, T.; Brabec, C. J. Photophysics of Molecular-Weight-Induced Losses in Indacenodithienothiophene-Based Solar Cells. Adv. Funct. Mater. 2015, 25 (30), 4898-4907.

(60) Zhang, W.; Han, Y.; Zhu, X.; Fei, Z.; Feng, Y.; Treat, N. D.; Faber, H.; Stingelin, N.; McCulloch, I.; Anthopoulos, T. D.; Heeney, M. A Novel Alkylated Indacenodithieno[3,2-b]thiophene-Based Polymer for High-Performance Field-Effect Transistors. Adv. Mater. 2016, 28 (20), 3922-3927.

(61) Dang, D.; Chen, W.; Himmelberger, S.; Tao, Q.; Lundin, A.; Yang, R.; Zhu, W.; Salleo, A.; Müller, C.; Wang, E. Enhanced Photovoltaic Performance of Indacenodithiophene-Quinoxaline Copolymers by Side-Chain Modulation. Adv. Energy Mater. 2014, 4 (15), 1400680 .

(62) Pilgram, K.; Zupan, M.; Skiles, R. Bromination of 2,1,3benzothiadiazoles. J. Heterocycl. Chem. 1970, 7 (3), 629-633.

(63) Huang, J.; Niu, Y.; Yang, W.; Mo, Y.; Yuan, M.; Cao, Y. Novel Electroluminescent Polymers Derived from Carbazole and Benzothiadiazole. Macromolecules 2002, 35 (16), 6080-6082.

(64) Herguth, P.; Jiang, X.; Liu, M. S.; Jen, A. K.-Y. Highly Efficient Fluorene- and Benzothiadiazole-Based Conjugated Copolymers for Polymer Light-Emitting Diodes. Macromolecules 2002, 35 (16), 60946100.

(65) Gao, X.; Shen, J.; Hu, B.; Tu, G. A Straightforward Synthesis of Chlorine-Bearing Donor-Acceptor Alternating Copolymers with Deep Frontier Orbital Levels. Macromol. Chem. Phys. 2014, 215 (14), 13881395.

(66) Crouch, D. J.; Skabara, P. J.; Lohr, J. E.; McDouall, J. J. W.; Heeney, M.; McCulloch, I.; Sparrowe, D.; Shkunov, M.; Coles, S. J.; Horton, P. N.; Hursthouse, M. B. Thiophene and Selenophene Copolymers Incorporating Fluorinated Phenylene Units in the Main Chain: Synthesis, Characterization, and Application in Organic FieldEffect Transistors. Chem. Mater. 2005, 17 (26), 6567-6578.

(67) Petrone, A.; Lingerfelt, D. B.; Rega, N.; Li, X. From chargetransfer to a charge-separated state: a perspective from the real-time TDDFT excitonic dynamics. Phys. Chem. Chem. Phys. 2014, 16 (44), 24457-24465.

(68) Wang, E.; Bergqvist, J.; Vandewal, K.; Ma, Z.; Hou, L.; Lundin, A.; Himmelberger, S.; Salleo, A.; Müller, C.; Inganäs, O.; Zhang, F.; Andersson, M. R. Conformational Disorder Enhances Solubility and Photovoltaic Performance of a Thiophene-Quinoxaline Copolymer. Adv. Energy Mater. 2013, 3 (6), 806-814.

(69) Dang, D.; Chen, W.; Himmelberger, S.; Tao, Q.; Lundin, A.; Yang, R.; Zhu, W.; Salleo, A.; Müller, C.; Wang, E. Enhanced Photovoltaic Performance of Indacenodithiophene-Quinoxaline Copolymers by Side-Chain Modulation. Adv. Energy Mater. 2014, 4 (15), 1400680.

(70) Park, J. K.; Jo, J.; Seo, J. H.; Moon, J. S.; Park, Y. D.; Lee, K.; Heeger, A. J.; Bazan, G. C. End-capping effect of a narrow bandgap conjugated polymer on bulk heterojunction solar cells. Adv. Mater. 2011, 23 (21), 2430-2435.

(71) Kim, S.; Park, J. K.; Park, Y. D. Charge transport behaviors of end-capped narrow band gap polymers in bottom-contact organic field-effect transistors. RSC Adv. 2014, 4 (74), 39268-39272.

(72) Koldemir, U.; Puniredd, S. R.; Wagner, M.; Tongay, S.; McCarley, T. D.; Kamenov, G. D.; Müllen, K.; Pisula, W.; Reynolds, J. R. End Capping Does Matter: Enhanced Order and Charge Transport 
in Conjugated Donor-Acceptor Polymers. Macromolecules 2015, 48 (18), 6369-6377.

(73) Gao, X.; Hu, B.; Tu, G. Straight forward synthesis of conjugated polymers for deep red to NIR PLED containing chlorine atoms on the backbone. Org. Electron. 2014, 15 (7), 1440-1447.

(74) Li, Y.; Yao, K.; Yip, H.-L.; Ding, F.-Z.; Xu, Y.-X.; Li, X.; Chen, Y.; Jen, A. K.-Y. Eleven-Membered Fused-Ring Low Band-Gap Polymer with Enhanced Charge Carrier Mobility and Photovoltaic Performance. Adv. Funct. Mater. 2014, 24 (23), 3631-3638.

(75) Fang, J. F.; Matyba, P.; Edman, L. The Design and Realization of Flexible, Long-Lived Light-Emitting Electrochemical Cells. Adv. Funct. Mater. 2009, 19 (16), 2671-2676.

(76) Tang, S.; Edman, L. Quest for an Appropriate Electrolyte for High-Performance Light-Emitting Electrochemical Cells. J. Phys. Chem. Lett. 2010, 1 (18), 2727-2732.

(77) Fang, J.; Matyba, P.; Robinson, N. D.; Edman, L. Identifying and alleviating electrochemical side-reactions in light-emitting electrochemical cells. J. Am. Chem. Soc. 2008, 130 (13), 4562-4568.

(78) van Reenen, S.; Janssen, R. A. J.; Kemerink, M. Fundamental Tradeoff between Emission Intensity and Efficiency in Light-Emitting Electrochemical Cells. Adv. Funct. Mater. 2015, 25 (20), 3066-3073.

(79) AlTal, F.; Gao, J. Long-term testing of polymer light-emitting electrochemical cells: Reversible doping and black spots. Org. Electron. 2015, 18, 1-7.

(80) Madigan, C. F.; Lu, M. H.; Sturm, J. C. Improvement of output coupling efficiency of organic light-emitting diodes by backside substrate modification. Appl. Phys. Lett. 2000, 76 (13), 1650-1652.

(81) Gu, G.; Garbuzov, D. Z.; Burrows, P. E.; Venkatesh, S.; Forrest, S. R.; Thompson, M. E. High-external-quantum-efficiency organic light-emitting devices. Opt. Lett. 1997, 22 (6), 396-398.

(82) Tang, S.; Buchholz, H. A.; Edman, L. On the selection of a host compound for efficient host-guest light-emitting electrochemical cells. J. Mater. Chem. C 2015, 3 (31), 8114-8120. 